American Journal of Economics and Business Administration 1 (3): 206-212, 2009

ISSN 1945-5488

(C) 2009 Science Publications

\title{
Genetically Modified Organism Trade Route and Biosafety-Is It a Failing Synthesis?
}

\author{
Debdatta Dobe and Rohini Sen \\ Old NIFT Building, E-4 GIDC, Electronics Estate, Gandhinagar-382028 \\ Gujarat, India
}

\begin{abstract}
Problem statement: GM regulations have spawned international conflicting reactions especially between US and EU, with countries requiring food aid caught midway. This article covers the following issues: Whether biotechnology policies of other countries affect the developing countries' trade in agricultural crops?" Does unregulated GM expansion and contamination, render the system fallacious? Can there be synthesis between trade and environment? Approach: This article also explores "long term effects of trading substitute GM components. Extensive research has been followed to identify the key areas of international trade and environment pertaining to GMO's which require immediate international attention. Results: The biotech war emerged with the Cartagena Protocol which permits countries to ban unsafe GM products and requires labeling of shipments that threaten traditional crops or biodiversity. In response to stricter stand of EU banning most GMOs, the US initiated litigation before WTO which in a preliminary ruling declared EU restriction violative of trade rules. Fear of export losses discourages Asia to approve new GMOs. U N reports that, Asia's regulatory framework is flawed and large number of tests, required to approve GMO's safe release are not conducted causing "irreversible loss of genetic diversity". Governments address these concerns differentially. Countries like Canada, China, and US incorporated GMOs commercially. While EU and Japan wait for full environmental assessment, the EU has issued a Directive on release and commercialization of GM crops. The EU view sharply contrasts to the WTO's, whose contribution to sustainable development of the environment lies in trade opening in goods and innovations like GM crops. WTO does not accept the process of production as cause for trade restrictions, narrowly interpreting the exception to trade rules under Article XX. International regulations on GMOs, (considered similar to harmful agricultural crops) are undefined. Before NAFTA, corporations are challenging these as "barriers to trade" while Environmentalists are advocating the "precautionary principle". Conclusion/Recommendations: The current climate of controversy in such key aspects across the world complicates the possibility of synthesis of trade and bio safety of GM food. Furthermore, the concept of food aid ensures that GM trade remains prevalent and unchecked. Thus, the answer to the projected environmental damage through such passage and the co-existence of trade laws alongside bio-safety demands an alteration in national as well as WTO legislations. This article attempts to evaluate the possibilities of a legislative make-over and the nuances of environmental safeguards against the proposed problems.
\end{abstract}

Key words: GMO, trade, biosafety, environment, Cartagena protocol, WTO

\section{INTRODUCTION}

An overview of the general concepts and issues: Genetically modified organism: Means an organism where the genetic material is altered unnaturally through fertilization and/or recombination. GMOs may be plants, animals or micro-organisms ${ }^{[1]}$. Using genetic engineering techniques, known as recombinant DNA technology, DNA molecules from different sources are combined into one molecule to create a new set of genes. This is then transferred into an organism, giving it modified or novel genes ${ }^{[2]}$. Transgenic plants are engineered to possess several desirable traits, including resistance to pests, herbicides or harsh environmental conditions, improved product shelf-life and increased nutritional value ${ }^{[3]}$ allowing genes to cross species barriers.

The use of GMOs has sparked controversy ${ }^{[4]}$. Studies about the effects of GM corn pollen on monarch butterfly caterpillars ${ }^{[5]}$, expanding cotton cultivation in Mali, resulting in land degradation and soil erosion, cross-pollination of organisms causing

Corresponding Author: Debdatta Dobe, Old NIFT Building, E-4 GIDC, Electronics Estate, Gandhinagar-382028, Gujarat, India 
financial and genetic diversity losses, open field trial effect on agro-biodiversity ${ }^{[6]}$ have brought the issue of genetic engineering to the forefront. The safety of GMOs in the food-chain has been questioned, with concerns such as GMOs introducing new allergens into foods, or spreading antibiotic resistance $\mathrm{e}^{[7]}$. An irreversible loss of genetic diversity through the release of GMOs is the most serious hazard to be confronted hugely impact the farming environment ${ }^{[8]}$. In Canada, $73 \%$ of the oilseed rape area is now GM, resulting in almost complete contamination of non-GM seed stocks $^{[9]}$. In 2007, post-harvest GM contamination of organic soybeans cost a food company $\$ 100,000$. Commercial release of GM papaya has breached environmental regulations alongside trade barriers.

\section{The trade laws and GMOs:}

A general overview: A country's right to set its own environmental and food safety regulations is provided for in article XX of the GATT. But WTO members have trade obligations under other GATT Articles (MFN, national treatment, customs transparency) and under other WTO agreements (most notably the SPS and TBT) that restrict the extent to which trade measures can be used against GMOs without risking litigation before the WTO's Dispute Settlement Understanding. According to free trade principles on which GATT and its successor, the WTO is based, countries cannot restrict imports excepting limited cases such as protection of health and safety of their citizens. In fact the WTO panel has interpreted narrowly the exception to trade rules under Article XX. The Agreement on the Application of Sanitary and Phytosanitary Measures which entered into force in 1995, establishes that countries retain their right to ensure that the food, animal and plant products they import are safe. At the same time it states that countries shouldn't use unnecessarily stringent measures as disguised trade barriers.

An important element of the WTO's contribution to sustainable development of the environment comes in the form of furthering trade opening in goods and services to promote economic development and by providing stable and predictable conditions that enhance innovation. The introduction of GM crops is seen as one such tool thus excess restriction is not encouraged.

The international trade regulations with regard to GM crops do not have a defined standard. Under WTO rules, the product process is not ground for trade restrictions. Only if the product itself is harmful can a country impose controls. To meet this objective, three international standard-setting bodies are identified: The
Codex Alimentarius Commission for food safety, the International Office of Epizootics for animal health and the IPPC for plant health. These guidelines indicate that the safety assessment process for GMOs should be conducted through comparing it with its traditional counterpart. By implementing standards, countries can reach the desired level of protection. If they differ from these standards, the measures should be justified and based on risk assessment.

International trade of GMOs: Do conventions address environmental effects of GMOs?: Several international agreements address environmental aspects of GMOs including the Convention on Biological Diversity (CBD), the Cartagena Protocol on Biosafety and the International Plant Protection Convention (IPPC).

The CBD mainly concerns itself with conservation and sustainable use of ecosystems but also addresses environmental effects of GMOs.

The objective of the Cartagena Protocol is to protect biodiversity from the risks posed by transfer, handling and use of GMOs. The protocol sets out an Advance Informed Agreement procedure for the intentional introduction of species that may have adverse environmental effects. It requires advance notification by the exporting party and a receipt notice by the importing party. It requires registration of relevant information under article 11 of the Protocol with the Bio-safety Clearing House. A developing country contracting party, or a party lacking domestic regulatory framework, can declare through the same that its decision on import of an GMO for direct use as food, feed or processing will be following a risk assessment. The Protocol also contains provisions on GMO handling, packaging and transportation as under Article 18.

International Plant Protection Convention aims to secure common international action to prevent the spread of pests affecting plants, but also plays a role in plant diversity conservation and natural resource protection. Although the IPPC makes provision for trade in plants, regarding GMOs, the IPPC has identified potential pest risks that need to be addressed: new genetic characteristics that may cause invasiveness, gene flow and effects on non-target organisms.

European and American conflict: GM regulations fuelled internationally conflicting reactions especially between US and EU, with countries requiring food aid caught midway. US claim these regulations violate free trade agreements, while the EU counter-positions that 
free trade isn't possible without informed consent. Consumers are demanding right to be informed of GMO in food consumed. Agricultural trade between the US and the European is estimated at $\$ 57$ billion and some in the US (farmers and food manufacturers) are concerned that the EU's proposal could bar much of that trade. European consumers are demanding food regulation, while the American agro industry, arguing for free trade is strongly opposed to labeling ${ }^{[10]}$. The main difference between the approaches lies in the fact that, the American agricultural industry is using trade agreements to determine domestic health, safety and environmental rules, rather than internal legislation because they fear having to distinguish energy and toxic standards as required by EU. The Cartagena Protocol attempts to set certain safety standards for GMO's in order to keep the trade-environmental symbiosis intact. However, the US didn't sign it. The American Agricultural Department claim mandatory labeling a trade barrier besides being expensive. US laws don't require GMOs to be labeled or traced because they believe GM crops pose no unique risks over conventional food ${ }^{[11]}$. Europe on the other hand, contends that labeling and traceability requirements are not only limited to GM food, but to all agricultural goods. Such labeling has been mandatory in Australia.

Americans view the ban over agro-biotechnology as breaching the WTO rules. The European position toward GMO was thought as leading to starvation in the developing world, as seen in some famine-threatened African countries that refuse to accept US aid because it contains GM food.

In May, following the conflict between US and EU, US filed a challenge with WTO disputing Europe's GM policy. The WTO has made a preliminary ruling that European Union restrictions on genetically engineered crops violate international trade rules. The US, Canada and Argentina together grow $80 \%$ of all commercial biotech crops, by which the EU regulates such crops. The countries argued that the EU's regulatory process was far too slow and its standards unreasonable given that scientific evidence find the crops safe.

European proposal over GM food: The EU's Committee on Environment, Public Health and Food Safety, implemented in 2003, requires that all food/feed containing or derived from GMOs be labeled and GM ingredients in food be traced. New EU regulations will require strict labeling and traceability of all food and animal feed containing more than $0.5 \%$ GMO and documentation tracing biotechnological products through the grain handling and food production processes. The new proposal particularly affects US maize gluten and soybean exports, as a high percentage of these crops are genetically modified.

In 1998, a de facto moratorium led to the suspension of approvals of new GMOs in the European Union pending the adoption of revised rules to govern the approval, marketing and labeling of biotech products. Imports and cultivation of pre-approved GMOs continued $^{[12]}$.

GMOs in trade disputes: Consumer resistance over GMOs resulted in marketing policies that could disrupt trade and international negotiations. Research highlighted three dispute areas: (1) technical aspects of GMOs and their international impacts, (2) property rights surrounding GMOs and identity preservation costs for keeping marketing channels segmented and (3) consumer education related to GMOs.

Consumer Education plays a pivotal role in the trade dispute concerning GMOs. It has been found that the resistance to GMOs is much greater in Europe, Japan and Taiwan than in US. In Europe and particularly in the UK, there is less trust of regulatory oversight of the food chain ${ }^{[13]}$. A larger measure of food is produced by small, local growers using traditional methods. Consumers, in general, are inadequately educated about biotechnology ${ }^{[14]}$.

Furthermore, the proliferation of domestic biosafety schemes and the authorization, labeling, traceability and documentation obligations have further complicated international trade in GM agricultural products and indirectly affected conventional agricultural trade ${ }^{[15]}$.

Existing GMO legislations: The EU's Environment Committee of the European Parliament in 2003 voted for stronger laws governing GMOs providing for better consumer choice and action to protect non-GMO and organic farmers from contamination. US, has three government agencies having jurisdiction over GM foods. The EPA evaluates GM plants for environmental safety, the USDA evaluates whether the plant is safe to grow and the FDA evaluates whether the plant is safe to eat. Asia, China has published comprehensive new laws for increased food safety evaluation, monitoring, recall and disclosure of information. Japan's Ministry of Health and Welfare has announced that health testing of GM foods will be mandatory as of April 2001 as opposed to current trends. Brazil has partially banned GM crops and Brazilian Institute for the Defense of Consumers, in collaboration with Greenpeace, initiated litigation to prevent the importation of GM crops. The Canadian Environmental Protection Act (CEPA) of 
1988 formally recognizes biotechnology as a manufacturing process for products potentially posing environmental risks and requires environmental assessments. Latin America continues to successfully reduce levels of food-related diseases and increase international food export volumes. The UK government highlighted their GM policy in a Parliamentary statement in March 2004. Though finding no scientific case for a blanket ban on the cultivation of GMOs, they proposed GMOs be assessed for safety on a case-bycase basis. Hungary has a pre-existing Act on GMOs for three years, soon to be amended in accordance with Cartagena Protocol. The Czech Republic also has solid legislation, in compliance with the Protocol. Progress is also being made in Slovenia, where public opinion against GMO's is strong. The government does not allow field trials and draft legislation to control GMOs is under preparation. Mexico has also approved a Biosafety Law for Genetically-Modified Organisms. By contrast, in Romania-although the Romanian government approved a GMO law in early 2000, it was rejected by the Parliament.

\section{GMOs and environmental interface:}

Environmental and ecological impacts: The largescale growth of GMOs has positive and negative environmental effects. Direct effects are seen on organisms that feed on the crops. Wider effects are manifested on food chains produced by increases or decreases in numbers of other organisms. The combination of some GM crops with long-lasting herbicides was bad for biodiversity, using other GM crops without these herbicides increased biodiversity.

On our planet, $18 \%$ of the land mass is used for agricultural production. It is absolutely essential that the yield per unit of land increases beyond current levels. The human population is still growing and 70,000 $\mathrm{km}^{2}$ of agricultural land are lost annually to growth of cities and other non-agricultural uses; Consumer diets in developing countries are increasingly changing from plant-based proteins to animal protein, requiring greater amount of crop-based foods. If the rights to these tools are strongly and universally enforced then the potential applications of GM technologies are unlikely to benefit the less developed nations.

Possible effects of GMOs on the environment: All kinds of agriculture affect the environment, so also use of new genetic techniques in agriculture. Genetic engineering may accelerate the damaging effects, have the same impact, or contribute to more sustainable agricultural practices and the conservation of natural resources, including biodiversity.
Growing genetically modified plants in the field has raised concern for the potential transfer of genes from cultivated species to their wild relatives. However, many food plants are not native to their area of cultivation. Locally, they'll have no wild relatives to which genes could flow. Moreover, if it occurs, the hybrid plants would possibly not thrive in wilderness, because they would have characteristics advantageous in agricultural environments only. In future, GM plants may be equipped with mechanisms designed to prevent gene flow. This is important for the co-existence of GM and conventional crops, particularly so for medicinal or industrial use GM plants.

Iindirect environmental effects: Of GM crops include changes in agricultural or environmental practices associated with the new varieties. Whether the net effect of these changes will be positive or negative for the environment remains controversial, calling for more comparative analysis of new technologies and farming practices. The environmental benefits include less water contamination and less damage to non-target insects, in turn beneficial to biodiversity. Herbicide-tolerant crops are encouraging low-till agriculture, with resulting benefits on soil conservation. On the other hand greater use of herbicides could further erode farmland.

New GM crops are being developed that can withstand environmental stresses such as drought salinity ${ }^{[16]}$.

The implications of GM-technologies for animals: Animal feeds frequently contain GM crops and enzymes derived from GM micro-organisms. To date no negative effects on animals is recorded. It is unlikely that genes may transfer from plants to disease-causing bacteria through food chains. Nevertheless, genes which determine resistance to antibiotics that are critical for treating humans shouldn't be used in GM plants. As of 2004, no GM animals were used in commercial agriculture, but several livestock and aquatic species were under study. GM animals could have positive environmental impacts, through greater disease resistance and lower antibiotic usage. However, some genetic modifications could lead to more intensive livestock production and increased pollution $^{[17]}$.

Environmental impact assessment: Scientists concur that GMOs should be evaluated using scientific procedures, on a case-by-case basis depending on the species, characteristic and ecosystems. The use of GM plants should be compared to other agricultural practices and technology, in particular to conventional 
agriculture, which has already had a profound effect on the environment.

International guidelines for GMO assessment are well developed for food safety but not for environmental impacts. The FAO/WHO Codex Alimentarius Commission provides an international forum for the former. In the absence of international guidelines, environmental impact assessments differ in:

- The interpretation of data and what constitutes environmental risk

- The basis for comparison used: Comparing the use either with conventional agricultural or with noncultivated environments

- The extent to which small-scale laboratory and field trials can be used to extrapolate large-scale effects

Before a crop is declared environment friendly safety assessment is recommended. If any safety concern is identified, the risk associated with it should be characterized to determine effect on human health. Subsequent assessments should consider factors such as toxicity, allergenicity ${ }^{[18]}$, antinutrients and metabolites, the stability of the inserted gene and nutritional modification associated with genetic modification. If the entire assessment of these factors concludes that the GM food in question is as safe as its conventional counterpart, the food is then considered safe to eat.

Co-existence: The key to agricultural development: Trade analysts and environmentalists hold co-existence to be the key to development of free trade and prevention of the environmental hazards arising out of GMO trade.

Approaches to co-existence need to be developed in a transparent way, based on scientific evidence and in co-operation with all. Farmers should be able to choose their preferred production type without imposing the necessity to change pre-established production patterns in the neighborhood. National strategies should refer to the legal labeling thresholds and purity standards for GM food.

Measures should be efficient and cost-effective, without going beyond what is necessary to comply with EU threshold levels for GMO labeling. Continuous monitoring and evaluation and the timely sharing of best practices are indicated as imperatives for improving measures over time. It is regulated by Network Group for the Exchange and Coordination of Information Concerning Coexistence of Genetically Modified, Conventional and Organic Crops (COEXNET).
Principles for the risk analysis of foods derived from modern biotechnology: The Principles define modern biotechnology as in the Cartagena Biosafety Protocol and include principles on risk assessment, risk management and risk communication. The risk assessment principles clarify that it includes a safety assessment designed to identify whether a hazard, nutritional or other safety concern is present and, if so, to gather information on its nature and severity. A safety assessment should (a) account for intended and unintended effects, (b) identify new or altered hazards and (c) identify changes relevant to human health in key nutrients. It is to be an interactive process stimulating advice and stakeholder participation. Safety assessment reports and other aspects of the decisionmaking process should be available to the public.

The new labeling and traceability rules, which cover both food and feed, require any products with a GMO content of more than $0.9 \%$ to be labeled. Labeling is also required for products that have been derived from GMOs, but where the GM content might no longer be detectable (such as soy oil produced from genetically modified soy).

The threshold for the presence of unapproved GMOs is $0.5 \%$ provided that the GMOs have been judged as safe for human health and the environment by the relevant Scientific Committees or the European Food Authority. This amount will be set for 3 years. After 3 years, all food containing non-authorized GMO will be banned. However, animals fed with transgenic cereals are not covered by the labeling requirements.

Traceability of GMO products is mandatory, from sowing to final product. GMOs will compulsorily carry a special harmless DNA sequence identifying the origin of the crops, allowing regulators to spot contaminated crops and enabling products to be withdrawn from the food chain. A series of additional sequences of DNA with encrypted information could also be added to provide more data.

Following the entry into force of the new regulations, the first genetically modified food product (canned maize) since 1998 was approved for marketing in the European Union in May 2004. While a number of other biotech products have been approved since then, approvals remain controversial.

The battle against GMO trade and usage: Opponents of genetically modified food often refer to it as "Franken food". Developing countries want the socioeconomic impacts of GMOs to be taken into account during any assessment of their environmental risks, as well as provision in the Protocol for compensation in the event of accidents involving the 
transport of GMOs. The lack of agreement between developed and developing nations has intensified the conflict between trade and environmental concerns.

A 2008 review published by the Royal Society of Medicine noted that GM foods have been eaten by millions of people worldwide for over 15 years, with no reports of ill effects. A 2004 review of feeding trials found no differences among animals eating genetically modified plants. However, a 2009 review found that although most studies concluded that GM foods do not differ in nutrition or cause any detectable toxic effects in animals, some studies did report adverse changes at a cellular level caused by some GM foods. Pressure groups and consumer rights groups, such as the Organic Consumers Association and Greenpeace claim the long term health risks which GM could pose, or the environmental risks associated with GM, have not yet been adequately investigated. They also claim that truly independent research in these areas is systematically blocked by the GM corporations which own the GM seeds and reference materials.

The impact on developing countries: Agricultural biotechnology may become increasingly important for developing countries. However, specific work is needed on the breeds and species of importance in developing countries. Research has tended to focus on crops important to developed countries. Developing countries are host to the greatest array of agricultural biodiversity in the world, but little work has been done on characterizing these plant and animal species at the molecular level to assess their production potential and disease and environmental-stress resistance or to ensure long-term conservation.

The application of new molecular biotechnologies and new breeding strategies to the crops and livestock breeds of specific relevance to smallholder production systems in developing countries will probably be constrained in the near future for a number of reasons. These include lack of reliable longer-term research funding, inadequate technical and operational capacity, the low commercial value of the crops and breeds, lack of adequate conventional breeding programmes and the need to select in the relevant production environments. Nevertheless, developing countries are already faced with the need to evaluate Genetically Modified (GM) crops and will one day also need to evaluate the possible use of GM trees, livestock and fish. These innovations may offer opportunities for increased production, productivity, product quality and adaptive fitness, but they will certainly create challenges for the research and regulatory capacity of developing countries $^{[19]}$.
Those developing countries are net-exporters of GM-potential products and fortunate enough to benefit from this new technology in their domestic production the results also suggest, however, that developing countries that do not gain access to GM technology may lose in terms of economic welfare if they cannot guarantee that their exports entering the Western European markets are GMO-free ${ }^{[20]}$.

The Indian Diaspora: India has fielded a lot of controversies in GM laws. According to the International Food Policy Research Institute (IFPRI), cotton is the only GM crop India has approved thus far. India has a three tiered biotech regulatory system, the Institutional Bio-safety Committee (IBC), the Review Committee on Genetic manipulation (RCGM) and the Genetic Engineering Approval Committee (GEAC). India's biotech regulatory system has been under relentless attack by the anti-GM groups for not banning field trials of GMOs.

However GMOs may bring benefits to India. Current practices of India's dry-land crop farmers are damaging to rural ecosystems. If GM crops produce yield gains for these farmers, there would be less need to clear new lands in rural India, plow fragile slopes, or destroy more habitats. If farmers had insecticidal GM crops they also might escape having to risk their own health, pollute the environment and kill so many nontarget species with chemical spray.

\section{CONCLUSION}

Biotechnology is a complement not substitute for conventional agriculture. Proponents claim genetic modification is less harsh on the environment than other technologies, such crops needing less repeated tilling and leading to less erosion also contributing to sustainable development and greater food production. To date, countries where GMOs have been introduced in fields, have reported no health damage or environmental harm. Moreover, farmers' using fewer pesticides, reduces harm to water supplies and workers' health and allows return of beneficial insects ${ }^{[21]}$.

The emergence of GMOs has generated policy reactions, consumers choosing between Western Europe's ban on importation of products from countries adopting GMO technology and another where there is a partial switch by consumers away from imports that contain GMOs. While government regulation ensures consumer and environmental health, growing consumer concerns demand transparency of the regulatory process.

However, the lack of observed negative effects does not mean that they cannot occur. Scientists call for 
a cautious case-by-case assessment of each product or process prior to its release in order to address legitimate safety concerns ${ }^{[22]}$. Society will have to take the final decision.

\section{REFERENCES}

1. European Food Safety Authority, 2009. Genetically modified organisms.

http://www.efsa.europa.eu/EFSA/efsa_locale1178620753812_1178621456978.htm

2. Sarad R. Parekh, 2004. The GMO Handbook: Genetically Modified Animals, Microbes and Plants in Biotechnology. Human Press Inc., ISBN: 1-59259-801-3, pp: 3.

3. Genetically Modified Organisms, 2009. http://en.wikipedia.org/wiki/Genetically_modified_ organisms" GM food controversy Health risks and benefits.

http://en.wikipedia.org/wiki/GM_food_controversy \#Health_risks_and_benefits

4. Cohen, S.N., A.C.Y. Chang, H.W. Boyer and R.B. Helling, 1973. Construction of biologically functional bacterial plasmids in vitro. Proc. Natl. Acad. Sci. USA., 70: 3240-3274.

5. Losey, J.E., L.S. Rayor and M.E. Carter, 1999. Transgenic pollen harms monarch larvae. Nature, 399: 399.

6. Sianesi, B. and D. Ulph, 1998. Species loss throught the genetic modification of crops: A policy framework. CSERGE Working Paper GEC pp: 98-25.

7. Bakshi, A., 2003. Potential adverse health effects of genetically modified crops. J. Toxicol. Environ. Health B Crit. Rev., 6: 211-225.

8. UNEP/Bio.Div/SWGB.1/2, 1990. Note to UNEP on basic issues with respect to biotechnology and conservation of biological diversity. Proceeding of the Ad Hoc Working Group of Experts on Biological Diversity, Subworking Group on Biotechnology, Nov. 14-16 United Nations Environment Programme, Nairobi, pp: 32.

9. Baranger, A., A.M. Chevre, F. Eber and M. Renard, 1995. Effect of oilseed rape genotype on the spontaneous hybridization rate with a weedy species: An assessment of transgenic dispersal. Theor. Applied Genet., 91: 956-963.

10. Thompson, L., 2000. Are bio engineered foods safe? FDA Consumer. http://www.cfsan.fda.gov/ dms/fdbioeng.html

11. USDA., 1986. US regulatory oversight in biotechnology. http://www.aphis.usda.gov/biotech/OECD/usregs.htm
12. Von Schomberg, R., 1998. An appraisal of the working in practice of directive 90/220/EEC on the deliberate release of genetically modified organisms. STOA Report of the European Parliament.

http://www.europarl.europa.eu/stoa/publications/st udies/19971101_en.pdf

13. Grove-White, R., P. Macnaghton, S. Mayer and B. Wynne, 1998. Uncertain world. Genetically modified organisms: Food and public attitudes in Britain. Centre for the Study of Environmental Change, Lancaster University, Lancaster.

14. UK Advisory Committee on Release to the Environment, 1998. Genetically modified crops: wider issues-Biodiversity in the agricultural environment.

http://www.environment.detr.gov.uk/acre/index.htm

15. Lang, A., E. Lauber and B. Darvas, 2007. Early tier tests insufficient for GMO risk assessment. Nat. Biotechnol., 25: 35-36.

16. Helge Torgersen, Gerhard Soja, Ines Janssen and Helmut Gaugitsch, 1997. Ecological impacts of traditional crop plants-a basis for the assessment of transgenic plants. BioSafety J., 3. http://library.coastweb.info/7572/

17. Tim O'Brien, 1995. Gene transfer and the welfare of farm animals: A compassion in world farming trust report.

http://openlibrary.org/b/OL17476484M/Gene_trans fer_and_the_welfare_of_farm_animals

18. Clydesdale, F.M., 2000. Allergenicity of foods produced by genetic modification. Food Sci. Nutr., 36: 165-186.

19. Magaña-Gómez, J.A., 2001. Risk assessment of genetically modified crops for nutrition and health. Nutr. Rev., 67: 1-16.

20. OECD., 1993. Safety evaluation of foods derived by modern biotechnology: Concepts and Principles.

http://www.agbios.com/docroot/articles/oecd_fsafe ty_1993.pdf

21. Flachowsky, G., A. Chesson and K. Aulrich, 2005. Animal nutrition with feeds from genetically modified plants. Arch. Anim. Nutr., 59: 1-40.

22. Rodriguez, N., 2003. Safety assessment and feeding value for pigs, poultry and ruminant animals of pest protected (Bt) plants and herbicide tolerant (Glyphosate, Glufosinate) plants: Interpretation of experimental results observed worldwide on Gm plants. Italian J. Anim. Sci., 3: 107-121.

http://www.aspajournal.it/archivio/pdf_2004/2_200 4/articolo-01.pdf 